\title{
High prevalence of exercise-induced heart failure with normal ejection fraction in post-heart transplant patients
}

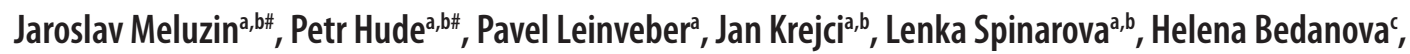 \\ Helena Podrouzkova ${ }^{a}$, Radka Stepanovad ${ }^{d}$ Petr Nemec ${ }^{c}$
}

\begin{abstract}
Aim. Post-heart transplant patients are at increased risk of diastolic dysfunction. The aim of this study was to assess the prevalence of isolated only exercise-induced heart failure with normal ejection fraction (HFNEF) in heart transplant recipients.

Methods and Results. To determine pulmonary capillary wedge pressure (PCWP) at rest and during exercise, 81 patients after orthotopic heart transplantation with normal left ventricular ejection fraction (LVEF) underwent exercise right heart catheterization with simultaneous exercise echocardiography. Based on PCWP values, the patients were divided into three groups. Twenty-one patients had no evidence of HFNEF (PCWP at rest $<15 \mathrm{mmHg}$, maximal PCWP during exercise $<25 \mathrm{mmHg}$, prevalence $26 \%$ ). Forty-seven subjects were found to have only exercise-induced HFNEF (PCWP at rest $<15 \mathrm{mmHg}$, maximal PCWP during exercise $\geq 25 \mathrm{mmHg}$, prevalence $58 \%$ ). Thirteen patients had HFNEF already at rest (PCWP $\geq 15 \mathrm{mmHg}$ at rest, prevalence $16 \%$ ). Of the noninvasive parameters obtained at rest, multivariate regression analysis identified LV mass index adjusted for allograft age to be an independent predictor of exercise-induced HFNEF.
\end{abstract}

Conclusions. In heart transplant recipients with normal LVEF, there is a high prevalence of exercise-induced HFNEF. LV mass index adjusted for allograft age is predictive of exercise-induced HFNEF.

Key words: heart transplantation, heart failure, pulmonary capillary wedge pressure, diastolic dysfunction

Received: August 30, 2013; Accepted: December 13, 2013; Available online: January 27, 2014

http://dx.doi.org/10.5507/bp.2013.095

${ }^{a}$ Department of Cardiovascular Diseases, ICRC, St. Anne's Hospital in Brno, Czech Republic

${ }^{b}$ Department of Cardiovascular Diseases, Faculty of Medicine, Masaryk University, Brno

'Centre of Cardiovascular and Transplant Surgery, ICRC, St. Anne's Hospital in Brno

'ICRC, St. Anne's Hospital in Brno

"The authors contributed equally to this article

Corresponding author: Jaroslav Meluzin, e-mail:jaroslav.meluzin@fnusa.cz

\section{INTRODUCTION}

Heart failure with normal left ventricular ejection fraction (HFNEF) is a frequent disease affecting up to $50 \%$ of patients with clinical features of heart failure ${ }^{1}$. Even if their risk of death is lower than that of patients with heart failure and reduced left ventricular ejection fraction (LVEF), the absolute mortality of patients with HFNEF is still high ${ }^{2}$ and requires new approaches in the prevention and treatment to improve prognosis. A basic step in the diagnostics of HFNEF is evidence of an increase in the LV filling pressure (LVFP) suggesting clinically significant LV diastolic dysfunction ${ }^{3}$. However, a significant proportion of patients suffer from heart failure symptomatology only during exercise. Borlaug et al. ${ }^{4}$ demonstrated the need for exercise to diagnose HFNEF in $58 \%$ of patients with unexplained dyspnea and normal hemodynamics at rest. The exercise may be particularly useful in post heart transplant patients with unexplained exertional dyspnea or fatigue. Heart transplant recipients frequently suffer from a number of risk factors of diastolic dysfunction such as hypertension, LV hypertrophy, myocardial fibrosis, diabetes mellitus, obesity, post-transplant vasculopathy, etc. and, therefore, are at a high risk of exercise-induced HFNEF. The aim of our study was to assess the prevalence of isolated, only exercise-induced HFNEF in patients after orthotopic heart transplantation and to determine independent predictors of exercise HFNEF development.

\section{MATERIALS AND METHODS}

\section{Patient population}

The study comprised 81 patients after orthotopic heart transplantation, who were referred to St. Anne's Hospital (Brno, Czech Republic) for post-transplant cardiac examination and gave their informed consent to the examinations, including simultaneous exercise right heart catheterization and echocardiography. All patients were regularly followed up at this hospital within the long-term programme of care for patients after heart transplantation. Coronary angiography was performed 12 months after the transplantation and repeated later if clinically indicated. The inclusion criteria were: a time interval $\geq 6$ months after heart transplantation; a sinus rhythm on the electrocardiogram; no history of myocardial infarction or angina pectoris after heart transplantation and a standard 
transthoracic echocardiogram demonstrating a normal LVEF ( $\geq 50 \%$ ), no significant pericardial effusion, and no mitral regurgitation other than trivial. The study complied with the Declaration of Helsinki and was approved by the ethics committee at St. Anne's Hospital in Brno.

\section{Study protocol}

Initially, standard transthoracic echocardiography was performed to determine whether the patients fulfilled echocardiographic inclusion criteria. On the following day, supine resting, exercise and recovery echocardiography and right heart catheterization with pulmonary capillary wedge pressure (PCWP) measurements were performed simultaneously. Examinations were performed in the morning after at least a 30-min rest. Measurements of PCWP, heart rate and blood pressure were initially performed at rest in patients with legs in a horizontal position and then repeated at rest four to five min after patient's leg elevation due to preparation for cycling. The same measurements were made during exercise at the end of each workload, at the time of termination of exercise (peak exercise), and at the end of each min of the postexercise recovery period until PCWP normalization. At both resting positions, at peak exercise and at the end of post-exercise recovery period, echocardiographic recordings of transmitral and mitral annular tissue Doppler velocities were obtained simultaneously with PCWP measurements. In patients referred for endomyocardial biopsy, several specimens were collected after finishing the study. On the day of catheterization, the morning medication was omitted.

\section{Right heart catheterization}

A 7F Swan-Ganz thermodilution catheter (model 131HF7, Baxter Healthcare Corporation, Irvine, CA, USA) was inserted into the pulmonary capillary wedge position. The correct balloon position was verified by the presence of characteristic wedge pressure waveforms. PCWP was measured with a zero level at the midaxillary line. PCWP, heart rate, and systemic blood pressure measurements were obtained using a multiparametric module Ultraview SL (TM) 91496 (Spacelabs Healthcare, Issaquah, WA, USA). PCWP was averaged over pressure waveform data obtained during a 12-s interval and expressed as a mean.

\section{Echocardiography}

Echocardiographic examinations were performed using Vivid E9 (GE Healthcare, Wauwatosa, WI) with an M5S transducer. At rest, grey-scale two-dimensional images were recorded from the parasternal short axis views at the base, at the level of papillary muscles and at the apex, as well as from the apical two-, three-, and four-chamber views. Three to five consecutive cardiac cycles in each view were digitally stored. Aortic and transmitral flows were recorded using pulsed-wave Doppler echocardiography. Pulsed-wave Doppler tissue imaging (DTI) of mitral annular motion was performed in the apical four-chamber view. A sample volume of $6.0 \mathrm{~mm}$ was placed on septal and lateral mitral annular corners. All Doppler recordings were done during shallow respiration or end-expiratory apnea. During the exercise, LV filling was monitored in the apical four-chamber view. The acquisition of peak exercise images started at the time of termination of cycling.

\section{Exercise protocol}

Graded supine bicycle ergometry limited by the onset of symptoms was performed starting at $25 \mathrm{~W}$ for two min. The load was then increased in increments of $25 \mathrm{~W}$ at twomin intervals until the occurrence of the first symptom (dyspnea or fatigue). All exercise tests were performed on an ergometer Ergoline GmbH (type er900L, Bitz, Germany). The patients were lying and cycling with their trunk in a horizontal position with their legs slightly elevated.

\section{Echocardiographic parameters analyzed}

Measurements were performed according to recommendations of the American Society of Echocardiography ${ }^{5}$. The data were analyzed offline using EchoPAC PC versions 108.1.5 - 110.1.1 (GE Vingmed Ultrasound A/S, Horten, Norway). LV mass was estimated using Devereux formula ${ }^{6}$. LV and left atrial (LA) volumes were calculated by means of the biplane method of disks $^{5}$ using apical four- and two-chamber views. From the conventional pulsed-wave Doppler recordings, the peak early diastolic transmitral flow velocity $(\mathrm{E})$, the peak late diastolic transmitral flow velocity (A), and the deceleration time of E wave (DT) were measured. From DTI, peak systolic and early diastolic mitral annular velocities at the septal corner and at the lateral corner were measured and the values were averaged ( $\mathrm{s}^{\prime}$ and $\mathrm{e}^{\prime}$ ). All echocardiographic parameters were obtained as a mean of three to six consecutive heart cycles. The analyses were performed by one experienced observer (JM), who was blinded to PCWP values. The variability of resting and exerciseinduced Doppler results of this reader has already been published $^{7}$. Mean absolute differences of intra-observer repeated measurements for both resting and exercise E, $e^{\prime}, s^{\prime}$ did not exceed $5 \%$.

\section{Definition of heart failure with normal left ventricular ejection fraction}

HFNEF is defined by the presence of a history of exertional dyspnea and/or by the evidence of a low exercise tolerance $(<100 \mathrm{~W}$ using the above described exercise protocol), by the finding of non-dilated left ventricle (enddiastolic volume index $<97 \mathrm{~mL} / \mathrm{m}^{2}$ ) with normal $\mathrm{LVEF}>$ $50 \%$, and by the evidence of diastolic dysfunction ${ }^{3}$ indicated by invasively measured PCWP elevation. PCWP at rest $\geq 15 \mathrm{mmHg}$ and/or maximal exercise PCWP $\geq 25 \mathrm{mmHg}$ were considered elevated and indicative of HFNEF (ref. ${ }^{4}$ ).

\section{Statistical analysis}

The baseline clinical characteristics, echocardiographic data, PCWP, and hemodynamic results were analyzed descriptively and compared between groups. Univariate and multivariate logistic regressions were used to determine predictors and independent predictors of exercise-induced HFNEF. Standard measures of summary statistics 
were used to describe the primary data: relative and absolute frequencies for categorical variables, arithmetic mean supplied with standard error of the mean (SEM) for continuous variables. Most variables did not present normal distribution (Shapiro-Wilk's test), therefore, nonparametric tests were applied. For the comparison of all three groups in continuous parameters, the Kruskal-Wallis test was conducted. For the detailed mutual comparison of the groups, the Wilcoxon Rank Sum test was performed. The Chi-square test was applied for categorical data. To determine independent predictors of the isolated, only exercise-induced HFNEF, univariate and multivariate regression analyses were performed in patients with a normal PCWP at rest $(<15 \mathrm{mmHg})$. Clinical data and resting echocardiographic and hemodynamic parameters were included. For parameters with potential predictive power (providing at least $P<0.10$ in univariate logistic regression), various multivariate models were used. Odds ratios (OR), their 95\% confidence intervals, and p-values are presented. Receiver operating characteristic (ROC) curves were constructed to identify sensitivities, specificities, areas under the curve (AUC), and the optimal cut-off values of independent predictors of the presence of exercise-induced HFNEF. Results with a $P$-value $<0.05$ were considered statistically significant.

\section{RESULTS}

Prevalence of isolated only exercise-induced heart failure with normal ejection fraction

Out of the 87 initially screened patients, 81 subjects fulfilled the inclusion criteria and were included in this study. According to the resting (patients in a horizontal position) and maximal exercise PCWP values, the patients were divided into three groups. Group A comprised 21 patients without HFNEF (PCWP at rest $<15 \mathrm{mmHg}$, maximal exercise PCWP $<25 \mathrm{mmHg}$ ), Group B included 47 patients with exercise-induced HFNEF (PCWP at rest $<15 \mathrm{mmHg}$, maximal exercise $\mathrm{PCWP} \geq 25 \mathrm{mmHg}$ ), and Group C comprised 13 patients with HFNEF at rest (PCWP at rest $\geq 15 \mathrm{mmHg}$ ). All Group B and C patients reported a history of exertional dyspnea and/or had a low exercise tolerance due to fatigue and/or shortness of breath. The distribution of patients in relation to HFNEF diagnosis is demonstrated in Fig. 1.

All patients were transplanted using the bicaval technique $^{8}$ and were on a combination of at least two immunosuppressive drugs. At the time of this study, endomyocardial biopsy was performed in 57 (70\%) patients; according to the modified ISHLT histological classification of cellular rejection ${ }^{9}, 27$ patients had grade 0,21 patients grade $1 \mathrm{~A}$, seven patients grade $1 \mathrm{~B}$, and two patients had grade 2 rejection. The distribution of rejection episodes in individual groups at the time of evaluation is demonstrated in Table 1. Sixty-one patients underwent coronary angiography (16 Group A, 34 Group B, and 11 Group C patients). Only four of them (one Group A, two Group $\mathrm{B}$, and one Group $\mathrm{C}$ patients, $P=\mathrm{NS}$ ) were found to have significant coronary vasculopathy (luminal diameter narrowing of at least one major coronary artery $\geq 50 \%$ ).

\section{Clinical characteristics of Group A, B, and C patients}

Table 1 summarizes the baseline clinical characteristics of Groups A, B, and C. Group A patients were less frequently on angiotensin-converting enzyme inhibitors or angiotensin II receptor blockers than Group C patients. There were no significant differences between Groups A and B. Table 2 shows two-dimensional echocardiographic parameters related to the diagnostics of HFNEF or diastolic LV function as well as the most important pulsedwave and tissue Doppler resting and exercise parameters. Groups A, B, and C differed in many Doppler-derived parameters reflecting differences in LV diastolic function. Complete or nearly complete fusion of early and late diastolic velocities or the inferior quality of exercise images did not allow the assessment of exercise E, DT, s', and e' in $13,24,12$, and 13 transplanted subjects, respectively. Table 3 presents the hemodynamic and PCWP data obtained at rest and maximal or peak exercise results. As expected, patients with HFNEF (Groups B and C) had significantly higher LV filling pressures both at rest and mainly during exercise compared to Group A.

\section{Predictors of isolated exercise-induced heart failure with normal ejection fraction}

In the clinical setting, patients with PCWP elevation present even at rest (Group $\mathrm{C}$ in our study) do not require exercise to diagnose HFNEF. In contrast, the exercise is important in patients suspected of having HFNEF with a normal or borderline PCWP at rest. Thus, the ability of clinical variables and of hemodynamic and echocardiographic parameters obtained at rest to predict the exerciseinduced elevation of PCWP $\geq 25 \mathrm{mmHg}$ was analyzed in Groups A and B patients with resting PCWP $<15 \mathrm{mmHg}$. In a multivariate regression model without adjustment for parameters, only PCWP was found to be a significant independent predictor of exercise HFNEF (odds ratio $1.32,95 \%$ confidence interval 1.06-1.66, $P=0.014$ ).

After adjustment for allograft age, LV mass index (optimal cut-off $100 \mathrm{~g} / \mathrm{m}^{2}$ with a sensitivity of $76.2 \%$ and a specificity of $57.5 \%$, AUC 0.66 ) in addition to PCWP

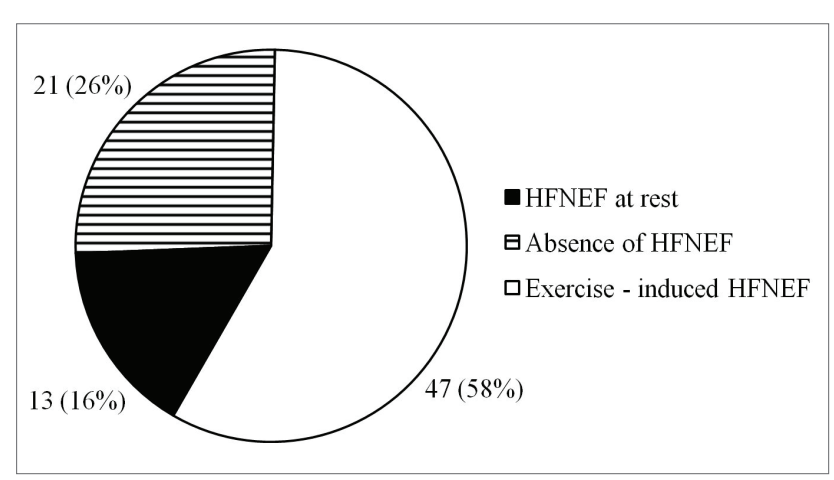

Fig. 1. Distribution of patients in relation to heart failure with normal ejection fraction (HFNEF). 
Table 1. Baseline clinical characteristics in transplanted patients without HFNEF (PCWP at rest $<15 \mathrm{mmHg}, \mathrm{PCWP}$ at peak exercise $<25 \mathrm{mmHg}$ ), with only exercise-induced HFNEF (PCWP at rest $<15 \mathrm{mmHg}$, PCWP at peak exercise $\geq 25 \mathrm{mmHg}$ ), and with HFNEF already at rest (PCWP at rest $\geq 15 \mathrm{mmHg}$ ).

\begin{tabular}{|c|c|c|c|c|}
\hline & $\begin{array}{l}\text { Absence } \\
\text { of HFNEF }\end{array}$ & $\begin{array}{c}\text { Exercise-induced } \\
\text { HFNEF }\end{array}$ & $\begin{array}{l}\text { HFNEF } \\
\text { at rest }\end{array}$ & \multirow[t]{2}{*}{$P$} \\
\hline & $(\mathrm{n}=21)$ & $(n=47)$ & $(\mathrm{n}=13)$ & \\
\hline \multicolumn{5}{|l|}{ Clinical characteristics: } \\
\hline Patient's age (years) & $51.9(2.33)$ & $54.4(1.81)$ & $55.7(2.82)$ & 0.448 \\
\hline Allograft age (years) & $41.1(3.23)$ & $40.8(1.72)$ & $43.9(3.36)$ & 0.668 \\
\hline Allograft ischemic time (min) & $144.0(12.44)$ & $159.7(7.90)$ & $146.5(13.97)$ & 0.480 \\
\hline Donor/recipient body weight ratio & $1.05(0.06)$ & $1.04(0.03)$ & $0.95(0.04)$ & 0.360 \\
\hline No. of rejections $\geq 1 \mathrm{~B}$ since OHT & $1.1(0.46)$ & $1.0(0.19)$ & $1.6(0.42)$ & 0.235 \\
\hline Time since OHT (months) & $49.1(10.92)$ & $48.1(8.11)$ & $68.9(13.24)$ & 0.128 \\
\hline Men (\%) & $19(90.5 \%)$ & $44(93.6 \%)$ & $11(84.6 \%)$ & 0.585 \\
\hline Hypertension (\%) & $18(85.7 \%)$ & $39(83.0 \%)$ & $10(76.9 \%)$ & 0.803 \\
\hline Hyperlipoproteinemia (\%) & $18(85.7 \%)$ & $43(91.5 \%)$ & $11(84.6 \%)$ & 0.678 \\
\hline Diabetes mellitus (\%) & $12(57.1 \%)$ & $25(53.2 \%)$ & $6(46.2 \%)$ & 0.823 \\
\hline Renal insufficiency (\%) & $5(23.8 \%)$ & $18(38.3 \%)$ & $5(38.5 \%)$ & 0.456 \\
\hline Body mass index $\left(\mathrm{kg} / \mathrm{m}^{2}\right)$ & $26.4(0.87)$ & $28.0(0.40)$ & $27.9(0.98)$ & 0.307 \\
\hline Rejection grade 0 & $9(42.9 \%)$ & $16(34.0 \%)$ & $2(15.4 \%)$ & 0.253 \\
\hline Rejection grade $1 \mathrm{~A}$ & $4(19.0 \%)$ & $15(31.9 \%)$ & $2(15.4 \%)$ & 0.342 \\
\hline Rejection grades $1 \mathrm{~B}$ or 2 & $3(14.3 \%)$ & $3(6.4 \%)$ & $3(23.1 \%)$ & 0.206 \\
\hline Exercise duration (s) & $319.0(12.84)$ & $336.0(9.84)$ & $324.0(18.65)$ & 0.556 \\
\hline \multicolumn{5}{|l|}{ Medical therapy } \\
\hline Calcineurin inhibitor (\%) & $21(100 \%)$ & $45(95.7 \%)$ & $12(92.3 \%)$ & 0.490 \\
\hline Mycophenolate (\%) & $20(95.2 \%)$ & $45(95.7 \%)$ & $11(84.6 \%)$ & 0.321 \\
\hline TOR inhibitor (\%) & $1(4.8 \%)$ & $3(6.4 \%)$ & $2(15.4 \%)$ & 0.474 \\
\hline Prednisone (\%) & $12(57.1 \%)$ & $28(59.6 \%)$ & $7(53.8 \%)$ & 0.929 \\
\hline ACEi or AT II (\%) & $8(38.1 \%)^{\dagger \dagger}$ & $29(61.7 \%)$ & $11(84.6 \%)$ & 0.024 \\
\hline Beta blocker (\%) & $13(61.9 \%)$ & $36(76.6 \%)$ & $11(84.6 \%)$ & 0.283 \\
\hline Diuretic (\%) & $9(42.9 \%)$ & $21(44.7 \%)$ & $4(30.8 \%)$ & 0.664 \\
\hline Statin (\%) & $21(100 \%)$ & $42(89.4 \%)$ & $12(92.3 \%)$ & 0.302 \\
\hline Aspirin (\%) & $17(81.0 \%)$ & $39(83.0 \%)$ & $13(100 \%)$ & 0.254 \\
\hline
\end{tabular}

ACEi, angiotensin-converting enzyme inhibitor; AT II, angiotensin II receptor blocker; HFNEF, heart failure with normal ejection fraction; OHT, orthotopic heart transplantation; PCWP, pulmonary capillary wedge pressure.

Data is presented as mean \pm SEM or number (\%). $P$, statistical test comparing all three groups; $\dagger \dagger P<0.01$ vs patients with HFNEF at rest.

(optimal cut-off $10 \mathrm{mmHg}$ with a sensitivity of $71.5 \%$ and a specificity of $59.6 \%$, AUC 0.69 ) were proved to be independent predictors. Results of the univariate and multivariate regression analyses after adjustment for donor heart age are demonstrated in Table 4.

\section{DISCUSSION}

Our study has provided some important facts and has one priority. To our knowledge, it is the first study to describe the high prevalence of isolated only exerciseinduced HFNEF reaching $58 \%$ in a cohort of 81 postheart transplant patients with normal LVEF. This finding explains their low exercise tolerance due to exertional dyspnea and/or fatigue. Of the noninvasive parameters obtained at rest, multivariate regression analysis identified LV mass index adjusted for allograft age to be the independent predictor of exercise-induced HFNEF.

\section{Aspects of left ventricular filling pressure elevation and development of heart failure with normal ejection fraction in post-heart transplant patients}

The most important aspects of LVFP elevation and development of HFNEF in the general population are hypertensive LV hypertrophy, myocardial fibrosis, vascular endothelial dysfunction, and changes in titin-based regulations of diastolic function ${ }^{10}$. All of these aspects may also play an important role in post-heart transplant patients being frequently influenced by risk factors of diastolic dysfunction such as hypertension, diabetes mellitus, obesity, and metabolic syndrome ${ }^{11-16}$. As demonstrated previously ${ }^{11}$ and confirmed in this study, systemic hypertension is a very common finding in patients after heart transplantation. Hypertension is frequently associated with LV hypertrophy which results in diastolic dysfunction $^{17,18}$. Severe LV hypertrophy is known to reduce subendocardial coronary flow reserve which can lead to subendocardial ischemia. Long-lasting hypertension is accompanied by a progression of myocardial fibrosis resulting in an increased myocardial stiffness. Moreover, 
Table 2. Two-dimensional and Doppler echocardiographic results in transplanted patients without HFNEF

(PCWP at rest $<15 \mathrm{mmHg}$, PCWP at peak exercise $<25 \mathrm{mmHg}$ ), with only exercise-induced HFNEF

(PCWP at rest $<15 \mathrm{mmHg}$, PCWP at peak exercise $\geq 25 \mathrm{mmHg}$ ), and with HFNEF already at rest (PCWP at rest $\geq 15 \mathrm{mmHg}$ ).

\begin{tabular}{|c|c|c|c|c|}
\hline & $\begin{array}{c}\text { Absence } \\
\text { of HFNEF }\end{array}$ & $\begin{array}{c}\text { Exercise-induced } \\
\text { HFNEF }\end{array}$ & $\begin{array}{l}\text { HFNEF } \\
\text { at rest }\end{array}$ & $P$ \\
\hline & $(\mathrm{n}=21)$ & $(n=47)$ & $(\mathrm{n}=13)$ & \\
\hline \multicolumn{5}{|c|}{ Two-dimensional echocardiography: } \\
\hline $\operatorname{EDVI}\left(\mathrm{mL} / \mathrm{m}^{2}\right)$ & $41.4(1.66)$ & $45.6(1.64)$ & $45.6(4.65)$ & 0.447 \\
\hline $\operatorname{ESVI}\left(\mathrm{mL} / \mathrm{m}^{2}\right)$ & $14.9(0.90)$ & $16.0(0.74)$ & $15.3(1.79)$ & 0.558 \\
\hline LVEF (\%) & $63.8(1.35)$ & $65.2(0.81)$ & $66.9(1.13)$ & 0.281 \\
\hline LAVI $\left(\mathrm{mL} / \mathrm{m}^{2}\right)$ & $41.0(1.85)$ & $43.7(1.70)$ & $48.5(3.71)$ & 0.286 \\
\hline $\operatorname{LVMI}\left(\mathrm{g} / \mathrm{m}^{2}\right)$ & $93.7(5.58)$ & $106.2(3.32)^{*}$ & $95.8(7.04)$ & 0.051 \\
\hline RWT & $0.526(0.019)$ & $0.537(0.015)$ & $0.500(0.018)$ & 0.447 \\
\hline \multicolumn{5}{|l|}{ Doppler parameters } \\
\hline E-rest $(\mathrm{cm} / \mathrm{s})$ & $73.1(3.91)^{\dagger \dagger}$ & $74.9(2.60)^{\dagger \dagger}$ & $97.6(6.53)$ & 0.003 \\
\hline E-ele $(\mathrm{cm} / \mathrm{s})$ & $86.7(3.42)^{\dagger}$ & $91.8(2.89)$ & $101.9(6.59)$ & 0.085 \\
\hline E-exe $(\mathrm{cm} / \mathrm{s})$ & $110.1(4.27)^{\dagger \dagger}$ & $123.8(2.70)^{* *}$ & $133.1(4.82)$ & 0.001 \\
\hline DT-rest (ms) & $163.4(6.34)^{\dagger \dagger}$ & $157.4(4.38)^{\dagger \dagger}$ & $136.6(5.56)$ & 0.007 \\
\hline DT-ele (ms) & $148.5(4.50)^{\dagger \dagger}$ & $136.2(3.53)$ & $128.8(4.43)$ & 0.028 \\
\hline DT-exe (ms) & $122.6(4.83)^{\dagger}$ & $108.9(2.47)^{* *}$ & $107.8(3.37)$ & 0.011 \\
\hline $\mathrm{e}^{\prime}-$ rest $(\mathrm{cm} / \mathrm{s})$ & $11.2(0.41)$ & $10.5(0.34)$ & $10.7(0.49)$ & 0.419 \\
\hline e'-ele $(\mathrm{cm} / \mathrm{s})$ & $12.2(0.48)$ & $11.6(0.34)$ & $11.2(0.59)$ & 0.365 \\
\hline e'-exe (cm/s) & $14.6(0.71)$ & $13.6(0.45)$ & $12.8(0.48)$ & 0.226 \\
\hline E-rest/e'-rest & $6.6(0.40)^{\dagger \dagger}$ & $7.4(0.34)^{\dagger \dagger}$ & $9.4(0.76)$ & 0.017 \\
\hline E-ele/e'-ele & $7.3(0.41)^{\dagger}$ & $8.2(0.33)$ & $9.6(0.90)$ & 0.052 \\
\hline E-exe/e'-exe & $7.8(0.45)^{\dagger \dagger}$ & $9.4(0.35)^{* *}$ & $10.5(0.51)$ & 0.001 \\
\hline $\mathrm{s}^{\prime}$-rest $(\mathrm{cm} / \mathrm{s})$ & $8.7(0.48)$ & $8.1(0.21)$ & $7.4(0.29)$ & 0.324 \\
\hline $\mathrm{s}^{\prime}$-ele $(\mathrm{cm} / \mathrm{s})$ & $8.9(0.50)$ & $8.0(0.25)$ & $7.4(0.31)$ & 0.178 \\
\hline $\mathrm{s}^{\prime}-\mathrm{exe}(\mathrm{cm} / \mathrm{s})$ & $10.7(0.56)$ & $10.2(0.37)$ & $9.6(0.53)$ & 0.454 \\
\hline
\end{tabular}

DT, deceleration time of E wave; E, peak early diastolic transmitral velocity; e', peak early diastolic mitral annular velocity; EDVI, end-diastolic volume index; ESVI, end-systolic volume index; ele, measured at rest with leg elevation; exe, measured at peak exercise; LAVI, left atrial volume index; LVEF, left ventricular ejection fraction; LVMI, left ventricular mass index; rest, measured at rest with legs in a horizontal position; RWT, relative wall thickness; s', peak systolic mitral annular velocity; Other abbreviations as in Table 1.

Data is presented as mean \pm SEM. $P$ : statistical test comparing all three groups; ${ }^{*} P<0.05$ vs patients with the absence of HFNEF; $* * P<0.01$ vs patients with the absence of HFNEF; $\dagger P<0.05$ vs patients with HFNEF at rest; $\dagger \dagger P<0.01$ vs patients with HFNEF at rest.

there are also specific factors directly related to heart transplantation that can further induce or accelerate diastolic dysfunction in cardiac allograft recipients ${ }^{19-27}$. These include myocardial denervation, volume overload due to a mismatch between the size of donor and recipient hearts $^{21}$, the effect of allograft ischemic time during the surgery ${ }^{22,26}$, pericardial constriction because of pericardial effusion ${ }^{25}$, acute cardiac rejection ${ }^{20,23,27}$, myocardial ischemia due to significant post-transplant vasculopathy, and immune heart injury associated with persistent tumor necrosis factor-alpha expression ${ }^{28}$. Serious risk factors for diastolic dysfunction are also progressive myocardial hypertrophy and fibrosis due to immune injury ${ }^{28}$, long donor heart ischemic time during surgery ${ }^{26}$, and due to healing of reccurent episodes of myocardial rejection ${ }^{24}$. Thus, owing to multiple potential risk factors, the post-heart transplant patients are at a high risk of both subclinical and manifest diastolic dysfunction and heart failure. Some of these risk factors, mainly early post-transplant immune reaction and the size of transplanted heart, are more important early after transplantation and are unlikely to significantly influence hearts late after transplantation. In the late post-transplant period, as found in the majority of our patients, myocardial ischemia due to vasculopathy and mainly progressive fibrosis and LV hypertrophy associated with repeated episodes of rejection and long-lasting hypertension likely become of greater importance. In our patients with PCWP $<15 \mathrm{mmHg}$ at rest, i.e. in those at risk of only exercise-induced LVFP elevation, resting PCWP and LV mass index both adjusted for donor heart age independently predicted exercise-induced HFNEF. LV mass index a quantitative measure of the severity of LV hypertrophy can easily be obtained noninvasively using standard echocardiography and its relationshisp to diastolic dysfunction is well established ${ }^{17,18,29}$. Thus, its elevation in transplanted patients with unexplained exertional dyspnea or fatigue may suggest the need for exercise to diagnose HFNEF.

\section{Left ventricular diastolic dysfunction in patients after orthotopic heart transplantation}

To date, a number of authors have described the presence of diastolic dysfunction both early and late after orthotopic heart transplantation ${ }^{23,24,27,30-36}$, frequently ac- 
Table 3. PCWP and hemodynamic results in transplanted patients without HFNEF (PCWP at rest $<15 \mathrm{mmHg}$, PCWP at peak exercise $<25 \mathrm{mmHg}$ ), with only exercise-induced HFNEF (PCWP at rest $<15 \mathrm{mmHg}$, PCWP at peak exercise $\geq 25 \mathrm{mmHg}$ ), and with HFNEF already at rest (PCWP at rest $\geq 15 \mathrm{mmHg}$ ).

\begin{tabular}{|c|c|c|c|c|}
\hline & $\begin{array}{l}\text { Absence of } \\
\text { HFNEF }\end{array}$ & $\begin{array}{c}\text { Exercise-induced } \\
\text { HFNEF }\end{array}$ & $\begin{array}{l}\text { HFNEF } \\
\text { at rest }\end{array}$ & $P$ \\
\hline & $(n=21)$ & $(\mathrm{n}=47)$ & $(n=13)$ & \\
\hline \multicolumn{5}{|l|}{ Right heart catheterization: } \\
\hline PCWP-rest (mmHg) & $8.6(0.68)^{\dagger \dagger}$ & $10.8(0.34)^{* *+\dagger}$ & $19.1(0.94)$ & $<0.001$ \\
\hline PCWP-ele (mmHg) & $11.5(0.81)^{\dagger \dagger}$ & $15.6(0.50)^{* *+\dagger}$ & $21.8(1.11)$ & $<0.001$ \\
\hline PCWP-max (mmHg) & $18.9(0.92)^{\dagger \dagger}$ & $29.4(0.46)^{* * \dagger \dagger}$ & $32.8(1.14)$ & $<0.001$ \\
\hline \multicolumn{5}{|l|}{ Hemodynamics: } \\
\hline Heart rate-rest (bpm) & $79.6(2.67)$ & $75.6(1.29)$ & $75.8(2.63)$ & 0.291 \\
\hline Heart rate-ele (bpm) & $79.3(2.69)$ & $75.8(1.29)$ & $76.5(2.55)$ & 0.392 \\
\hline Heart rate-exe (bpm) & $108.5(3.12)$ & $104.1(1.74)$ & $108.0(2.94)$ & 0.321 \\
\hline Systolic BP-rest (mmHg) & $134.1(2.76)$ & $140.3(2.16)$ & $138.2(4.86)$ & 0.283 \\
\hline Systolic BP-ele (mmHg) & $140.0(2.21)$ & $144.9(2.24)$ & $144.2(4.99)$ & 0.434 \\
\hline Systolic BP-exe (mmHg) & $154.0(3.50)$ & $157.5(2.79)$ & $160.4(4.94)$ & 0.588 \\
\hline Diastolic BP-rest (mmHg) & $90.3(2.12)$ & $90.6(1.13)$ & $86.8(3.11)$ & 0.395 \\
\hline Diastolic BP-ele (mmHg) & $91.8(1.99)$ & $91.3(1.24)$ & $93.2(3.63)$ & 0.814 \\
\hline Diastolic BP-exe (mmHg) & $97.6(2.95)$ & $96.8(1.70)$ & $94.5(3.04)$ & 0.750 \\
\hline
\end{tabular}

BP, blood pressure; max, maximal PCWP during exercise. Other abbreviations as in Tables 1 and 2. Statistical data presentation as in Table 2.

Table 4. Univariate and multivariate logistic regression, including potential exercise-induced HFNEF predictors adjusted for allograft age.

\begin{tabular}{lcccc}
\hline & \multicolumn{2}{c}{ Univariate logistic regression } & \multicolumn{2}{c}{ Multivariate logistic regression } \\
\cline { 2 - 5 } & $\begin{array}{c}\text { Odds ratio } \\
(95 \% \text { confidence interval })\end{array}$ & $P$ & Odds ratio \\
& $1.02(0.98-1.06)$ & 0.936 & $0.98(0.92-1.04)$ & 0.382 \\
\hline Allograft age (years) & $1.13(1.00-1.28)$ & 0.055 & $1.23(1.04-1.45)$ & 0.019 \\
LVMI $\left(\mathrm{g} / \mathrm{m}^{2}\right)$ & $1.35(1.10-1.66)$ & 0.004 & $1.45(1.12-1.87)$ & 0.005 \\
PCWP-rest $(\mathrm{mmHg})$ & &
\end{tabular}

For the parameter LVMI unit $5 \mathrm{~g} / \mathrm{m}^{2}$ was used in order to present odds for exercise-induced HFNEF if the value of LVMI is increased by $5 \mathrm{~g} / \mathrm{m}^{2}$. For all the other parameters unit 1 was used. Abbreviations as in Tables 2 and 3.

companied by PCWP elevation ${ }^{23,24,27,31,33-36}$. Impaired LV diastolic function in heart transplant recipients was found even if LVEF was normal ${ }^{30,32}$ and if there was no or only 1A myocardial rejection ${ }^{30}$. Diastolic dysfunction was attributed to both the worsening of relaxation ${ }^{37}$ and an increase in myocardial stiffness ${ }^{22,35}$. The common presence of structural post-transplant myocardial damage in the absence of myocardial rejection and without reduction of LVEF was also suggested by worsening of LV longitudinal systolic function which precedes the decrease in LVEF (ref. ${ }^{11,30}$ ). As LV systolic and diastolic functions are closely coupled ${ }^{38,39}$, worsening of the LV longitudinal systolic function can contribute to LV diastolic dysfunction.

There have been several reports on post-transplant exercise-induced LVFP changes ${ }^{19,21,37,40-42}$. However, these studies included small numbers of patients (the largest comprising 30 patients) and none assessed the prevalence of exercise-induced HFNEF. Rudas et al. ${ }^{40}$ described in 20 post-heart transplant recipients without rejection a significant increase in PCWP from $13 \pm 4 \mathrm{mmHg}$ to $27 \pm$ $7 \mathrm{mmHg}$ during supine graded exercise; results very similar to those found in our study. PCWP exercise-induced increase was attributed to abnormal left-shifted and steep diastolic pressure-volume relation in transplanted patients indicating abnormal cardiac compliance. Hosenpud et al. ${ }^{21}$ found PCWP increase from $10 \pm 3 \mathrm{mmHg}$ to $20 \pm 6$ $\mathrm{mmHg}$ during supine exercise in 23 patients with a normal LVEF at one year after heart transplantation. The greatest resting and exercise LVFP had patients with little or no change in end-diastolic volume on exercise. Paulus et al. ${ }^{37}$ studied 27 heart transplant recipients with a normal LVEF, who were free of rejection and of significant graft atherosclerosis. Supine exercise resulted in a smaller acceleration of LV relaxation than in a normal control group exercising to the same heart rate. There was a significant association between elevation in LV end-diastolic pressure (from $14 \pm 4 \mathrm{mmHg}$ to $25 \pm 7 \mathrm{mmHg}$ ) and slower LV isovolumic relaxation ${ }^{37}$. Thus, elevated LVFP 
during exercise can result not only from abnormal passive LV diastolic properties ${ }^{40}$ and preload reserve ${ }^{21}$, but also from altered LV relaxation ${ }^{37}$. To date, however, no study has focused on the prevalence of exercise-induced HFNEF in cardiac allograft recipients and on two-dimensional and Doppler echocardiographic predictors of exercise HFNEF. Our study, which included 81 post-heart transplant patients demonstrated a high prevalence of exercise-induced HFNEF. This diagnosis was carefully documented by the presence of exertional dyspnea and/or low exercise tolerance, by the evidence of non-dilated left ventricle with a normal LVEF, and by invasively measured PCWP both at rest and during exercise. The diagnosis of latent, only exercise-induced HFNEF can optimize patient management and prevent further heart failure progression. However, the exact clinical significance of this early HFNEF diagnosis has yet to be determined.

\section{Study limitations}

The sample of our patients after orthotopic heart transplantation was narrowed by the study inclusion criteria that primarily focused on the diagnostics of HFNEF. A study of unselected post-heart transplant patients would probably result in a different exercise-induced HFNEF prevalence. However, in view of a good LVEF in the majority of transplanted patients at the late follow-up, the high prevalence of exercise-induced HFNEF described in our study is undoubtedly a reality. Based on the results, we cannot determine the exact contribution of coronary vasculopathy and of acute allograft rejection to exerciseinduced HFNEF. Since $25 \%$ of patients did not undergo coronary angiography and others had a long-time interval (> one year) between this study and the last coronary angiography, we cannot exclude significant but clinically silent allograft vasculopathy in these patients resulting in a silent exercise-induced myocardial ischemia and diastolic dysfunction. Similarly, $30 \%$ of patients did not undergo endomyocardial biopsy at the time of measurement. This was mainly in patients with a long interval since the transplantation and with a low probability of rejection. However, a subclinical rejection at the time of study cannot be completely excluded in these patients.

\section{CONCLUSIONS}

In heart transplant recipients with normal LVEF, there is a high prevalence of exercise-induced HFNEF. The LV mass index adjusted for allograft age is predictive of exercise-induced HFNEF.

\section{ABBREVIATIONS}

A, Peak late diastolic transmitral flow velocity; DT, Deceleration time of early filling; DTI, Doppler tissue imaging; E, Peak early diastolic transmitral flow velocity; e', Peak early diastolic mitral annular velocity; HFNEF, Heart failure with normal ejection fraction; LV, Left ven- tricular; LVEF, Left ventricular ejection fraction; LVFP, Left ventricular filling pressure; PCWP, Pulmonary capillary wedge pressure; s', Peak systolic mitral annular velocity.

\section{ACKNOWLEDGMENTS}

We are grateful to Stepanka Kunakova and Lucie Cernoskova for their help with the right heart catheterizations. The study was supported in part by the European Regional Development Fund - Project FNUSA-ICRC (No. CZ.1.05/1.1.00/02.0123).

\section{CONFLICT OF INTEREST STATEMENT}

None declared.

\section{REFERENCES}

1. Owan TE, Hodge DO, Herges RM, Jacobsen SJ, Roger VL, Redfield MM. Trends in prevalence and outcome of heart failure with preserved ejection fraction. N Engl J Med 2006;355:251-9.

2. Meta-analysis Global Group in Chronic Heart Failure (MAGGIC). The survival of patients with heart failure with preserved or reduced left ventricular ejection fraction: an individual patient data metaanalysis. Eur Heart J 2012;33:1750-7.

3. Paulus WJ, Tschöpe C, Sanderson JE, Rusconi C, Flachskampf FA Rademakers FE, Marino P, Smiseth OA, De Keulenaer G, Leite-Moreire AF, Borbély A, Édes I, Handoko ML, Heymans S, Pezzali N, Pieske B, Dickstein K, Fraser AG, and Brutsaert DL. How to diagnose diastolic heart failure: a consensus statement on the diagnosis of heart failure with normal left ventricular ejection fraction by the Heart Failure and Echocardiography Associations of the European Society of Cardiology. Eur Heart J 2007;28:2539-50.

4. Borlaug BA, Nishimura RA, Sorajja P, Lam CSP, Redfield MM. Exercise hemodynamics enhance diagnosis of early heart failure with preserved ejection fraction. Circ Heart Fail 2010;3:588-95.

5. Lang RM, Bierig M, Devereux RB, Flachskampf FA, Foster E, Pellikka PA, Picard MH, Roman MJ, Seward J, Shanewise J, Solomon S, Spencer KT, Sutton MSJ, Stewart W. Recommendations for chamber quantification. Eur J Echocardiogr 2006;7:79-108.

6. Devereux RB, Alonso DR, Lutas EM, Gottlieb GJ, Campo E, Sachs I, Reichek N. Echocardiographic assessment of left ventricular hypertrophy: comparison to necropsy findings. Am J Cardiol 1986;57:4508

7. Meluzin J, Hude P, Krejci J, Spinarova L, Podrouzkova H, Leinveber P, Dusek L, Soska V, Tomandl J, Nemec P. Noninvasive prediction of the exercise-induced elevation in left ventricular filling pressure in post heart transplant patients with normal left ventricular ejection fraction. Exp Clin Cardiol 2013;18:63-72.

8. Sarsam MAI, Campbell CS, Yonan NA, Deiraniya AK, and Rahman AN. An alternative surgical technique in orthotopic cardiac transplantation. J Card Surg 1993;8:344-9.

9. Rodriguez ER. The pathology of heart transplant biopsy specimens: Revisiting the 1990 ISHLT working formulation. J Heart Lung Transplant 2003;22:3-15.

10. Phan TT, Shivu GN, Abozguia K, Sanderson JE, Frenneaux M. The pathophysiology of heart failure with preserved ejection fraction: From molecular mechanisms to exercise haemodynamics. Int J Cardiol 2012;158:337-43.

11. Pichler $P$, Binder $T$, Hofer $P$, Bergler-Klein J, Goliasch G, Lajic N, Aliabadi A, Zuckermann A, and Syeda B. Two-dimensional speckle tracking echocardiography in heart transplant patients: three-year follow-up of deformation parameters and ejection fraction derived from transthoracic echocardiography. Eur J Echocardiogr Cardiovasc Imaging 2012;13:181-6. 
12. Sánchez Lázaro IJ, Almenar Bonet L, Martínez-Dolz L, Moro López J, Aguero Ramón-Llín J, Cano Pérez O, Rueda Soriano J, Buendía Fuentes F, Navarro Manchón J, Sánchez Gómez JM, and Salvador Sanz A. Hypertension after heart transplantation: predictive factors and number and classes of drugs for its management. Transplant Proc 2008;40:3051-2.

13. Depczynski B, Daly B, Campbell LV, Chisholm DJ, and Keogh A. Predicting the occurrence of diabetes mellitus in recipients of heart transplants. Diabet Med 2000;17:15-9.

14. Corcos $T$, Tamburino $C$, Léger $P$, Vaissier $E$, Rossant $P$, Mattein MF Daudon P, Gandjbakhch I, Pavie A, Cabrol A, Cabrol Ch. Early and late hemodynamic evaluation after cardiac transplantation: a study of 28 cases. J Am Coll Cardiol 1988;11:264-9.

15. Armstrong AT, Binkley PF, Baker PB, Myerowitz PD, Leier CV. Quantitative investigation of cardiomyocyte hypertrophy and myocardial fibrosis over 6 years after cardiac transplantation. J Am Col Cardiol 1998;32:704-10.

16. Fort AC, Gavira JJ, Alegría-Barrero E, Castano S, Martín A, Ubilla M, Mastrobuoni S, Ezquerra EA, Herreros J, and Rábago G. Prevalence of metabolic syndrome in heart transplant patients: role of previous cardiopathy and years since the procedure-the TRACA study. J Heart Lung Transplant 2006;25:1192-8.

17. Betocchi S, Chiariello M. Effects of antihypertensive therapy on diastolic dysfunction in left ventricular hypertrophy. J Cardiovasc Pharmacol 1992;19(suppl.5):S116-S121.

18. Inouye I, Massie B, Loge D, Topic N, Silverstein D, Simpson P, and Tubau J. Abnormal left ventricular filling: an early finding in mild to moderate systemic hypertension. Am J Cardiol 1984;53:120-6.

19. Pflugfelder PW, McKenzie FN, Kostuk WJ. Hemodynamic profiles at rest and during supine exercise after orthotopic cardiac transplantation. Am J Cardiol 1988;61:1328-33.

20. Amende I, Simon R, Seegers A, Daniel W, Heublein B, Hetzer R, Haverich A, Hood Jr WP, Lichtlen PR, Schutzenmeister R, and Wenzlaff $P$. Diastolic dysfunction during acute cardiac allograft rejection. Circulation 1990;81 (suppl III):III-66-III-70.

21. Hosenpud JD, Morton MJ, Wilson RA, Pantely GA, Norman DJ, Cobanoglu MA, and Starr A. Abnormal exercise hemodynamics in cardiac allograft recipients 1 year after cardiac transplantation. Circulation 1989;80:525-32.

22. Hausdorf G, Banner NR, Mitchell A, Khaghani A, Martin M, Yacoub $M$. Diastolic function after cardiac and heart-lung transplantation. Br Heart J 1989;62:123-32.

23. Eun LY, Gajarski RJ, Graziano JN, and Ensing GJ. Relation of left ventricular diastolic function as measured by echocardiography and pulmonary capillary wedge pressure to rejection in young patients ( $\leq 31$ years) after heart transplantation. Am J Cardiol 2005;96:857-60.

24. Valantine HA, Appleton ChP, Hatle LK, Hunt SA, Billingham ME, Shumway NE, Stinson EB, and Popp RL. A hemodynamic and Doppler echocardiographic study of ventricular function in longterm cardiac allograft recipients. Circulation 1989;79:66-75.

25. Seacord LM, Miller LW, Pennington DG, McBride LR, and Kern MJ. Reversal of constrictive/restrictive physiology with treatment of allograft rejection. Am Heart J 1990;120:455-9.

26. Pickering JG, and Boughner DR. Fibrosis in the transplanted heart and its relation to donor ischemic time. Circulation 1990;81:949-58.

27. Davies RA, Koshal A, Walley V, Runstedler B, Green M, Morton B Jindal S, Beanlands D, and Keon W. Temporary diastolic noncompliance with preserved systolic function after heart transplantation. Transplant Proc 1987;19:3444-7.

28. Stetson SJ, Perez-Verdia A, Mazur W, Farmer JA, Koerner MM, Weilbaecher DG, Entman ML, Quinones MA, Noon GP, Torre-Amione
G. Cardiac hypertrophy after transplantation is associated with persistent expression of tumor necrosis factor-alpha. Circulation 2001; 104:676-81.

29. Lorell BH, Apstein CS, Weinberg EO, Cunningham MJ. Diastolic function in left ventricular hypertrophy: Clinical and experimental relationships. Eur Heart J 1990;11 (Suppl.G):54-64.

30. Goland S, Siegel RJ, Burton K, De Robertis MA, Rafique A, Schwarz E, Zivari K, Mirocha J, Trento A, Czer LSC. Changes in left and right ventricular function of donor hearts during the first year after heart transplantation. Heart 2011;97:1681-6.

31. Sundereswaran L, Nagueh SF, Vardan S, Middleton KJ, Zoghbi WA, Quinones MA, and Torre-Amione G. Estimation of left and right ventricular filling pressures after heart transplantation by tissue Doppler imaging. Am J Cardiol 1998;82:352-7.

32. Roten L, Schmid JP, Merz F, Carrel T, Zwahlen M, Walpoth N, Mohacsi $P$, and Hullin R. Diastolic dysfunction of the cardiac allograft and maximal exercise capacity. J Heart Lung Transplant 2009;28:434-9.

33. Tenderich G, Olatiu A, Zittermann A, Wellnhofer E, Koertke H, Koerfer R. Noninvasive echocardiographic estimation of pulmonary wedge pressure in candidates for and recipients of heart transplantation. J Am Soc Echocardiogr 2007;20:480-5.

34. López B, Sanchez V, Delgado JF, Casares SF, Mora L, García J, Lombera F, Forteza A, Cortina JM, and Saenz de la Calzada C. Accuracy of noninvasive estimation of pulmonary wedge pressure by echocardiographic indices in heart transplant recipients. Transplant Proc 2012;44:2639-41.

35. Pereira NL, Zile MR, Harley RA, and Van Bakel AB. Myocardial mechanisms causing heart failure early after cardiac transplantation. Transplant Proc 2006;38:2999-3003.

36. Young JB, Leon CA, Short HD, Noon GP, Lawrence EC, Whisennand $\mathrm{HH}$, Pratt CM, Goodman DA, Weilbaecher D, Quinones MA, and DeBakey ME. Evolution of hemodynamics after orthotopic heart and heart-lung transplantation: early restrictive patterns persisting in occult fashion. J Heart Transplant 1987;6:34-43.

37. Paulus WJ, Bronzwaer JG, Felice H, Kishan N, and Wellens F. Deficient acceleration of left ventricular relaxation during exercise after heart transplantation. Circulation 1992;86:1175-85.

38. Udelson JE, Bacharach SL, Cannon III RO, Bonow RO. Minimum left ventricular pressure during beta-adrenergic stimulation in human subjects. Evidence for elastic recoil and diastolic suction in the normal heart. Circulation 1990;82:1174-82

39. Vinereanu D, Nicolaides E, Tweddel A, Fraser AG. "Pure" diastolic dysfunction is associated with long-axis systolic dysfunction. Implications for the diagnosis and classification of heart failure. Eur J Heart Fail 2005;7:820-8.

40. Rudas L, Pflugfelder PW, Kostuk WJ. Comparison of hemodynamic responses during dynamic exercise in the upright and supine postures after orthotopic cardiac transplantation. J Am Coll Cardiol 1990;16:1367-73.

41. Kao AC, Van Trigt P III, Shaeffer-McCall GS, Shaw JP, Kuzil BB, Page RD, Higginbotham MB. Heart failure/cardiac transplantation/artificial heart disease: central and peripheral limitations to upright exercise in untrained cardiac transplant recipients. Circulation 1994;89:260515.

42. Hosenpud JD, Pantely GA, Morton MJ, Wilson RA, Norman DJ, Cobanoglu AM, and Starr A. Lack of progressive "restrictive" physiology after heart transplantation despite intervening episodes of allograft rejection: comparison of serial rest and exercise hemodynamics one and two years after transplantation. J Heart Transplant 1990;9:119-23. 